\title{
Mast cells: the forgotten cells of renal fibrosis
}

\author{
I S D Roberts, P E C Brenchley
}

\begin{abstract}
BackgroundlAims-Mast cells, when activated, secrete a large number of fibrogenic factors and have been implicated in the development of fibrotic conditions of the liver, lung, and skin. There is evidence that renal fibrosis is closely linked with a chronic inflammatory cell infiltrate within the interstitium, but a potential role for mast cells in this process has yet to be defined. Therefore, the numbers of mast cells in normal and fibrotic kidneys with various pathologies were investigated.
\end{abstract}

Methods-Mast cells were quantified in renal transplants showing acute and chronic rejection and cyclosporin toxicity, kidneys removed for chronic pyelonephritis, and renal biopsies from patients with IgA nephropathy, membranous nephropathy, and diabetic nephropathy. Mast cells were stained using two methods: acid toluidine blue detected less than $30 \%$ of the mast cells revealed by immunohistochemistry for mast cell tryptase.

Results-Mast cells were scarce or absent in normal kidney (median, 1.6 mast cells $/ \mathrm{mm}^{2}$ ) but numerous throughout the cortex and medulla in all specimens that showed fibrosis. They were almost entirely confined to the renal interstitium. Mast cells were present in large numbers in biopsies from patients with membranous nephropathy (median, 21.7 mast cells/ $\mathbf{m m}^{2}$ ) and diabetic nephropathy (median, 29.2 mast cells $/ \mathrm{mm}^{2}$ ), which were selected on the basis of showing chronic injury. In 24 unselected IgA nephropathy biopsies there was a close correlation between numbers of mast cells and the extent of interstitial fibrosis $(r=0.771 ; p<0.0001)$. In renal transplant biopsies, mast cells were associated with allograft fibrosis in chronic rejection (median, 27.1 mast cells/ $\mathbf{m m}^{2}$ ) and chronic cyclosporin toxicity (median, 10.6 mast cells $/ \mathrm{mm}^{2}$ ) but not acute rejection (median, 2.7 mast cells/ $\mathbf{m m}^{2}$ ) or acute cyclosporin toxicity (median, 2.0 mast cells $/ \mathrm{mm}^{2}$ ). There was no detectable increase in mast cell numbers during acute rejection in those transplants that subsequently progressed to chronic rejection. In some biopsies the mast cells were largely intact, but in most cases some or all were degranulated.

Conclusions-An increased number of mast cells is a consistent feature of renal fibrosis, whatever the underlying pathology, and the number of mast cells correlates with the extent of interstitial fibrosis.
This suggests that mast cells might play a pathogenetic role in the fibrotic process. (f Clin Pathol 2000;53:858-862)

Keywords: mast cells; kidney; fibrosis

Mast cells are a heterogenous group of cells, first identified by the dye binding characteristics of their proteoglycan rich granules. ${ }^{1-3}$ Their precursors originate from the bone marrow and circulate within peripheral blood ${ }^{4}$; the mature tissue mast cells are widespread, being present in virtually every organ in the body. In addition to glycosaminoglycans, mast cells store, or are capable of synthesising, a wide variety of proinflammatory and vasoactive mediators, cytokines, and enzymes. The varied activity of mast cell products and their potential biological functions are multiple and diverse and they have been implicated in many pathological situations. In addition to type I hypersensitivity reactions there is evidence that mast cells play a role in acute inflammation, ${ }^{6}$ modulation of cellular immune responses, ${ }^{7}$ angiogenesis, ${ }^{8}$ turnover of connective tissue, and fibrosis.

Mast cells are known to secrete a range of cytokines including interleukin 3 (IL-3), IL-4, IL-5, IL-13, ${ }^{9}$ IL-6, ${ }^{10}$ and IL-8. ${ }^{11}$ Similarly, human mast cells constitutively express vascular endothelial growth factor (VEGF) ${ }^{12}$ and basic fibroblast growth factor (bFGF), which is localised to $97 \%$ of tryptase positive mast cells in human fibrotic lung tissue. ${ }^{13}$ Mast cells also contain specific proteases that display a range of biological functions. Mast cell tryptase is a mitogen both for epithelial cells, stimulating the production of IL- 8 and intercellular adhesion molecule 1 (ICAM-1) expression, ${ }^{14}$ and for microvascular endothelial cells, inducing angiogenesis and capillary tube formation. ${ }^{15}$

Chemoattractant factors controlling mast cell recruitment into inflammatory lesions have been identified as extracellular matrix components, including laminin, ${ }^{16} \mathrm{c}$-kit ligand (stem cell factor), ${ }^{17}$ platelet derived growth factor (PDGF), bFGF, VEGF, ${ }^{18}$ and the most potent of all, transforming growth factor $\beta 1$ (TGF$\beta 1) .{ }^{19}$ In peripheral lung tissue from patients with chronic obstructive pulmonary disease, associated with increased numbers of tissue mast cells, intraepithelial mast cell numbers correlate with TGF- $\beta 1$ mRNA expression.

Mast cells have been implicated in pathological fibrosis in several conditions including hypertrophic scars, ${ }^{20}$ chronic atopic dermatitis, ${ }^{21}$ hepatic cirrhosis, ${ }^{22}$ fibrosing alveolitis, ${ }^{23}{ }^{24}$ and cardiac fibrosis. ${ }^{25}$ In lung allograft rejection their numbers increase with the severity of acute rejection and the greatest numbers are associated with chronic rejection. ${ }^{26}$ Mast cells 
might potentiate fibrosis by a variety of mechanisms. There is evidence that they are capable of synthesising several fibrogenic cytokines, including $\mathrm{bFGF}^{27}$ and TGF- $\beta 1{ }^{28}$ Mast cell proteases might also contribute to matrix remodelling and fibrosis; in vitro studies have demonstrated activation of matrix metalloproteinases by mast cell degranulation. ${ }^{29}$ Mast cell tryptase is a profibrogenic factor, stimulating type I collagen synthesis by fibroblasts ${ }^{30}$ and inducing chemotaxis in fibroblasts comparable to that of TGF- $\beta 1 .{ }^{31}$ Human mast cell chymase is effective at releasing latent TGF- $\beta 1$ from extracellular matrix but does not appear to convert TGF- $\beta 1$ to the active $25 \mathrm{kDa}$ species. ${ }^{32}$ Furthermore, histamine and heparin control fibroblast proliferation and stimulate collagen synthesis in vitro. ${ }^{33}$ Coculture of mast cells and fibroblasts results in fibroblast proliferation, which is modulated by direct cell-cell contact. ${ }^{35}$ Mast cell granules are phagocytosed by fibroblasts in coculture ${ }^{36}$ and ultrastructural studies have confirmed an intimate association between mast cells and fibroblasts in vivo. The interaction between mast cells and stromal cells has been studied in several pathological tissues, including haemangiomas, ${ }^{37}$ spindle cell lipomas, ${ }^{38}$ and neurofibromas. ${ }^{39}$ Intercellular contacts, membrane fusion, and endocytotic vesicles have been described, and it is possible that direct cell-cell contact might be more important than mast cell degranulation or cytokine secretion in the control of connective tissue turnover.

Renal fibrosis is the major cause of end stage renal failure. Glomerulonephritis, diabetic nephropathy, pyelonephritis, and renovascular disease together account for over $75 \%$ of patients requiring renal replacement treatment. ${ }^{40}{ }^{41}$ In these conditions, it is more commonly chronic progressive renal fibrosis, with associated loss of functioning nephrons, than a severe acute insult, that results in irreversible renal injury. There is abundant evidence that the long term outcome of chronic renal disease depends to a great extent upon changes within the tubulointerstitial compartment. This includes conditions in which the primary insult is within the glomeruli; the extent and severity of interstitial fibrosis and tubular atrophy are the most powerful histological markers of renal function and long term prognosis in chronic glomerulonephritis. ${ }^{42-44}$ Early on, this fibrotic process is characterised by an interstitial chronic inflammatory cell infiltrate and the proliferation of interstitial myofibroblasts. ${ }^{45-48}$ This is driven by a cytokine network that includes growth factors for myofibroblasts such as PDGF, bFGF, and TGF- $\beta 1$, an important trigger of matrix synthesis. $^{49}$ The tubular epithelium is an important source of cytokines that act on interstitial fibroblasts $\mathrm{s}^{50}$ and in addition stimulate the infiltration of T cells and macrophages, which then secrete several fibrogenic cytokines. ${ }^{51}{ }^{52}$ The epithelial cells are also capable of transdifferentiation into myofibroblasts ${ }^{53}$ and elaborating matrix proteins. ${ }^{54}$ In chronic glomerulonephritis, cytokines secreted by glomerular epithelial cells, together with fil- tered proteins, play a role in producing tubular epithelial cell injury and activation, thus providing a major trigger for the fibroinflammatory response within the interstitium. ${ }^{55}$

There is evidence that similar processes underlie the progressive interstitial fibrosis in chronic renal allograft rejection. Chronic rejection, the major cause of graft loss after renal transplantation, is characterised histologically by progressive vascular, glomerular, and interstitial fibrosis. As in native renal disease, TGF$\beta 1$, secreted by tubular epithelium and infiltrating leucocytes, might play a central role in driving new matrix production. ${ }^{56}$

Although there is an extensive literature on the role of lymphocytes and macrophages in the pathogenesis of renal fibrosis, a potential role of interstitial mast cells has been largely ignored. Other than within the matrix around the major vessels, mast cells are absent from normal kidney, but their role in renal disease is yet to be defined. Only recently has it been reported that mast cell infiltration is associated with chronic injury in diabetic nephropathy ${ }^{57}$ and $\operatorname{IgA}$ nephropathy ${ }^{58}$ Here, we report the quantification of renal mast cell infiltrates in several fibrotic conditions. We demonstrate that increased numbers of mast cells is a consistent feature of renal fibrosis, whatever the underlying pathology, and that the number of mast cells correlates with the extent of fibrosis.

\section{Methods}

TISSUES

Archival renal tissue, fixed in neutral buffered formalin $(10 \% \mathrm{vol} / \mathrm{vol})$ and embedded in paraffin wax, with the following diagnoses was used: "normal kidney" obtained from nephrectomy for renal cell carcinoma $(n=5)$; transplant nephrectomy for chronic vascular rejection $(n=5)$; nephrectomy for chronic obstructive pyelonephritis $(n=5)$; biopsies from renal transplants showing acute rejection $(n=19)$ and chronic vascular rejection $(n=8)$, acute cyclosporin toxicity $(n=13)$, and chronic cyclosporin toxicity $(n=12)$; and diagnostic renal biopsies from patients with IgA nephropathy $(\mathrm{n}=24)$, membranous nephropathy $(n=4)$, and diabetic nephropathy $(n=6)$. The acute rejection transplant biopsies were consecutive and unselected from 19 patients. Of these, eight patients subsequently developed biopsy confirmed chronic rejection (group 1). The eight biopsies showing chronic rejection were from this same group of patients. The remaining 11 patients (group 2) showed stable long term graft function. The IgA nephropathy biopsies were consecutive primary diagnoses over a two year period and were unselected. The membranous and diabetic nephropathy biopsies were selected on the basis of the haematoxylin and eosin sections showing mild to moderate chronic tubulointerstitial injury.

QUANTIFICATION OF MAST CELLS

The following two methods were used for the detection of mast cells in nephrectomy tissue: (1) $1 \%(\mathrm{wt} / \mathrm{vol})$ toluidine blue, $\mathrm{pH} 1.0$, staining time 30 minutes; and (2) immunohistochemistry for mast cell tryptase (Dako Ltd, High 
Table $1 \quad$ Numbers of mast cells detected by toluidine blue compared with mast cell tryptase immunostaining

\begin{tabular}{llll}
\hline \multirow{4}{*}{ Diagnosis } & \multicolumn{2}{l}{ Mast cells $/ \mathrm{mm}^{2}$ of cortex median (range) } \\
\cline { 2 - 4 } & Toluidine blue (pH 1.0) & Mast cell tryptase & p Value \\
\hline Normal kidney & $0.2(0-0.8)$ & $1.4(0.3-3.6)$ & 0.03 \\
CVR & $12.5(6.9-14.3)$ & $41.3(25.3-52.3)$ & $<0.01$ \\
CPN & $7(1.6-12)$ & $37.8(23.5-47.1)$ & $<0.01$ \\
\hline
\end{tabular}

p Values were calculated using the Mann-Whitney U test.

$\mathrm{CPN}$, chronic obstructive pyelonephritis; CVR, chronic vascular rejection.

Table 2 Numbers of mast cells detected in nephrectomy specimens using immunohistochemistry for mast cell tryptase

\begin{tabular}{llll}
\hline \multirow{4}{*}{ Diagnosis } & \multicolumn{4}{l}{ Mast cells/mm $m^{2}$ median (range) } \\
\cline { 2 - 4 } & Outer cortex & Inner cortex & Medulla \\
\hline Normal kidney & $2.5(0.3-4.3)$ & $0.3(0.3-3.8)$ & $1.0(0-5)$ \\
CVR & $35(15.3-53.3)$ & $47(29-51.3)$ & $22.5(15.3-39.8)$ \\
CPN & $30.5(23.5-41.8)$ & $48.1(32.5-63.8)$ & $45.3(23.8-55)$
\end{tabular}

CVR and CPN $v$ normal kidney: $\mathrm{p}<0.01$ for cortex and medulla; CVR $v$ CPN, not significant. $\mathrm{CPN}$, chronic obstructive pyelonephritis; CVR, chronic vascular rejection.

Wycombe, UK) using a standard immunoperoxidase technique. Sections were pretreated with hyaluronidase. The toluidine blue stain detected only a small proportion of the total mast cells present (table 1) and in all renal biopsies mast cells were detected immunohistochemically. In biopsy material the entire renal cortex was examined. In nephrectomy tissue mast cells were counted in $20 \times 40$ objective fields of the outer cortex (within two $\times 40$ objective fields of the renal capsule), inner cortex (within two $\times 40$ objective fields of the corticomedullary junction), and outer medulla. Numbers of mast cells $/ \mathrm{mm}^{2}$ were then calculated; each field had an area of $0.4 \mathrm{~mm}^{2}$.

MORPHOMETRIC ANALYSIS

Biopsies on which the diagnosis of $\operatorname{IgA}$ nephropathy was made were analysed further to determine the extent of interstitial fibrosis. A Chalkley 25 point graticule (Graticules Ltd, Tonbridge, UK) was used to calculate the area of the interstitium, expressed as a percentage of the total renal cortical area. Periodic acid Schiff stained sections from each biopsy were used. Fields containing large arteries were excluded but otherwise the entire renal cortex in each biopsy was analysed. None of the biopsies showed pronounced oedema and, therefore, the interstitial area was a measure of the extent of interstitial fibrosis.

\section{Results}

NEPHRECTOMY SPECIMENS

In the "normal" renal tissue, obtained from kidneys that contained renal cell carcinomas, mast cells were present within the matrix around lobar and arcuate arteries, but absent from both the cortex and medulla, other than in small foci of subcapsular fibrosis. In contrast, large numbers of mast cells were present within the interstitium of kidneys showing chronic allograft rejection and chronic obstructive pyelonephritis (table 2; fig 1A and B). In chronic rejection, numbers of mast cells were generally greater in the cortex than in the medulla. There was no significant difference in numbers between the inner and outer cortex.
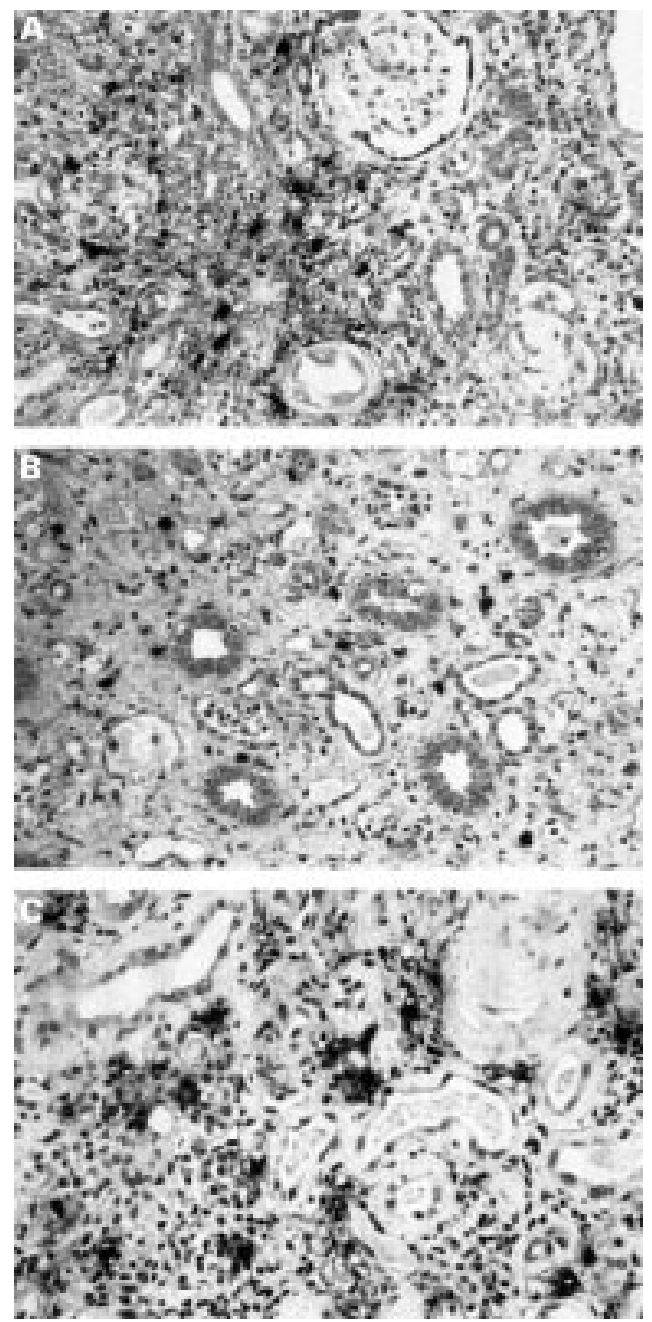

Figure 1 Mast cell infiltration in $(A)$ the cortex and $(B)$ the medulla in chronic renal allograft rejection. $(C ; \operatorname{Ig} A$ nephropathy) Cortical interstitial mast cells frequently show evidence of degranulation, with positivity for tryptase seen in the surrounding matrix.

Mast cells were rarely seen in the glomeruli and tubules.

\section{GLOMERULONEPHRITIS}

Mast cells were present in large numbers within the interstitium in biopsies from patients with membranous nephropathy (median, 21.7 mast cells $/ \mathrm{mm}^{2}$; range, 11.9-33.3) and diabetic nephropathy (median, 29.2 mast cells/ $\mathrm{mm}^{2}$; range, 3.2-34.3). In the IgA nephropathy biopsies, there was a close correlation between numbers of mast cells and the extent of interstitial fibrosis (fig 2). In some biopsies the mast cells were largely intact, but in most cases some or all showed evidence of degranulation (fig 1C).

\section{ALLOGRAFT BIOPSIES}

Mast cells were sparse in transplant biopsies showing acute rejection and acute cyclosporin toxicity (table 3). There was no difference in mast cell numbers between the acute rejection biopsies from group 1, patients who subsequently developed chronic vascular rejection, and those from group 2 with long term stable graft function. The subsequent biopsies 


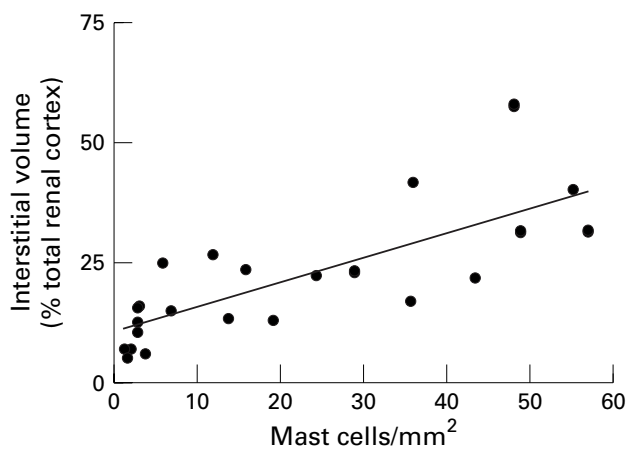

Figure 2 Correlation of numbers of mast cells with cortical interstitial area, expressed as a percentage of the total renal cortex, in IgA nephropathy. Pearson's correlation: $r=0.771 ; p<0.0001$

showing chronic rejection from group 2 patients contained large numbers of interstitial mast cells, as did the biopsies that showed chronic cyclosporin toxicity (table 3 ). Of the biopsies with chronic cyclosporin toxicity, five exhibited mild chronic allograft nephropathy (grade 1) and these contained fewer mast cells (median, $7.5 / \mathrm{mm}^{2}$ ) than the seven biopsies that showed chronic cyclosporin toxicity and chronic allograft nephropathy, grade $2-3$ (median, $15.4 / \mathrm{mm}^{2}$ ), but this difference was not significant.

\section{Discussion}

We have demonstrated that an interstitial infiltrate of mast cells is a consistent feature of renal fibrosis, whatever the aetiology, and that the number of mast cells present correlates closely with the extent of fibrosis. The presence of mast cells is not confined to immune mediated or postinflammatory fibrosis, as indicated by increased numbers in chronic cyclosporin toxicity, in the absence of rejection.

The study of the role of mast cells in human pathology has been facilitated by the availability of antibodies to mast cell tryptase, an enzyme specific for mast cells, which can be used in formalin fixed tissues. The formalin sensitivity of traditional histochemical stains for mast cells, such as toluidine blue and alcian blue, has long been recognised ${ }^{59}$ and prevents the accurate quantification of mast cells in routinely processed tissue. Our initial quantification of toluidine blue stained mast cells in nephrectomy specimens indicates that around $75 \%$ of renal mast cells are formalin sensitive.

In renal allografts that show progression from acute to chronic rejection mast cells are not seen until the chronic phase, indicating that

Table 3 Numbers of mast cells in renal allograft biopsies

\begin{tabular}{lll}
\hline Biopsy diagnosis & $\begin{array}{l}\text { Mast cells/mm }{ }^{2} \text { of cortex } \\
\text { median (interquartile range) }\end{array}$ & $p$ Value $^{\star}$ \\
\hline AR $(\rightarrow$ CVR) & $3.0(1.9-5.1)$ & AR $v$ CVR \\
AR (no CVR) & $2.7(1.0-5.3)$ & $<0.0001$ \\
CVR & $27.1(20.7-29.8)$ & $\begin{array}{l}\text { Acute } v \text { chronic cyclosporin } \\
\text { toxicity } \\
\text { Acute cyclosporin toxicity }\end{array}$ \\
& $2.0(1.3-2.5)$ & $<0.0001$
\end{tabular}

$\mathrm{p}$ Values were calculated using the Mann-Whitney U test.

$\mathrm{AR}$, acute rejection; CPN, chronic obstructive pyelonephritis; CVR, chronic vascular rejection. it is fibrosis itself, rather than the inflammatory process, that is the major stimulus for mast cell recruitment. It has been proposed that mast cells are a result, rather than a cause, of tissue fibrosis. ${ }^{60}$ However, in many of the renal tissues studied there is evidence of extensive mast cell degranulation. In view of the profibrotic properties of mast cell products it appears likely that these cells play an active pathogenetic role in the fibrotic process, rather than being merely innocent bystanders. Ehara et al reported bFGF production by interstitial mast cells in renal fibrosis associated with $\operatorname{IgA}$ nephropathy. ${ }^{58}$ We suggest that transiently increased TGF- $\beta 1$ expression and activation in acute inflammation and immune responses is insufficient to establish a chemoattractant gradient necessary to sustain mast cell influx because of competition for the bioactive TGF- $\beta 1$ from resident fibroblasts, smooth muscle and endothelial cells, and infiltrating leucocytes. However, in a scenario of continued activation of TGF- $\beta 1$ at the site of persistent chronic inflammation, high concentrations of bioactive TGF- $\beta 1$ can bind to heparan sulphate glycosaminoglycan in the extracellular matrix ${ }^{61}$ and establish and sustain a haptotactic solid phase gradient, enabling mast cell recruitment. This mechanism is testable in models of TGF- $\beta 1$ transfection with the use of selective neutralising anti-TGF- $\beta 1$ antibodies.

Because many fibrogenic mast cell cytokines are also produced by other cell types involved in renal fibrosis, such as macrophages and tubular epithelial cells, it is difficult to define the precise role that mast cells play in the fibrotic process. One model that offers the potential for further investigation is the genetically mast cell deficient $\mathrm{W} / \mathrm{W}^{\mathrm{v}}$ mouse. ${ }^{62}$ If these animals show an impaired fibrogenic response after the induction of chronic renal injury that is not seen in the wild-type littermates with normal numbers of mast cells, and this is reversible after reconstitution with wild-type bone marrow cells, then an important role for mast cells in renal fibrosis is established. It has already been demonstrated in an animal model that cutaneous fibrosis may be inhibited by mast cell stabilising agents. ${ }^{63}$ If an active pathogenetic role for mast cells in renal fibrosis is demonstrated, these compounds offer the potential for a new approach to antifibrotic treatment in the management of chronic renal disease.

1 Ehrlich P. Beitrage zur Kenntnis der granulierten Bindegewebszellen und der eosinophilen Leukocythen. Arch Anat Physiol (Physiol Abt), reprinted in Himmelweit F, ed. The collected papers of Paul Ehrlich, Vol. 1. London: Pergamon Press, 1956:114-16.

2 Ehrlich P. Beitrage zur Kenntnis der Anilinfarbungen und ihrer Verwendung in der mikroskopischen Technik. Arch $\mathrm{Mkr}$ Anat, reprinted in Himmelweit F, ed. The collected papers of Paul Ehrlich, Vol. 1. London: Pergamon Press, 1956:19-28

3 Enerback L. Mast cell heterogeneity: the evolution of the concept of a specific mucosal mast cell. In: Beyfus AD, ed. Mast cell differentiation and heterogeneity. New York: Raven Press, 1986:1-26.

4 Horton MA, O'Brien HAW. Characterisation of human mast cells in long-term culture. Blood 1983;62:1251-60.

5 Kirshenbaum AS, Goff JP, Dreskin SC, et al. Interleukin 3-dependent growth of basophil-like and mast-like cells 3-dependent growth of basophil-like and mast-like cell
from human bone marrow. F Immunol 1982;142:2424-9.

6 Wershil BK, Murakami I, Galli SJ. Mast cell dependent amplification of an immunologically non-specific inflammatory response. F Immunol 1988;140:2356-60. 
7 Gershon RK, Askenase PW, Gershon MD. Requirement for vasoactive amines for production of delayed type hypersensitivity skin reaction. $\mathscr{F}$ Exp Med 1975;142:732-47.

8 Meninger CJ, Zetter BR. Mast cells and angiogenesis. Semin Cancer Biol 1992;3:73-9.

9 Burd PR, Thompson WC, Max EE, et al. Activated mast cells produce interleukin 13. F Exp Med 1995;181:137380.

10 Kruger-Krasagakes S, Moller AM, Kolde G, et al. Production of interleukin- 6 by human mast cells and basophilic cells. F Invest Dermatol 1996;10:75-9.

11 Grutzkau A, Kruger-Krasagakes S, Kogel H, et al. Detection of intracellular interleukin-8 in human mast cells: flow cytometry as a guide for immunoelectron microscopy. $\mathcal{F}$ Histochem Cytochem 1997;45:935-45.

12 Grutzkau A, Kruger-Krasagakes S, Baumeister H, et al. Synthesis, storage, and release of vascular endothelial growth factor/vascular permeability factor (VEGF/VPF) by human mast cells: implications for the biological significance of VEGF(206). Mol Biol Cell 1998;9:875-84.

13 Qu Z, Liebler JM, Powers MR, et al. Mast cells are a major source of basic fibroblast growth factor in chronic inflammation and cutaneous hemangioma. Am f Patho

14 Cairns JA, Walls AF. Mast cell tryptase is a mitogen for epithelial cells-stimulation of IL-8 production and intercellular adhesion molecule-1 expression. F Immunol 1996;156 275-83.

15 Blair RJ, Meng H, Marchese MJ, et al. Human mast cells stimulate vascular tube formation. Tryptase is a novel, potent angiogenic factor. $\mathcal{F}$ Clin Invest 1997;99:2691-700.

16 Thompson HL, Burbelo PD, Yamada Y, et al. Mast cells chemotax to laminin with enhancement after IgE-mediated activation. F Immunol 1989;143:4188-92

17 Flanagan JG, Leder P. The c-kit ligand: a cell surface molecule altered in steel mutant fibroblasts. Cell 1990;63: 185-94.

18 Gruber BL, Marchese MJ, Kew R. Angiogenic factors stimulate mast cell migration. Blood 1995;86:2488-93.

19 Gruber BL, Marchese MJ, Kew RR. Transforming growth factor-beta 1 mediates mast cell chemotaxis. 7 Immunol 1994;152:5860-7.

20 Smith CJ, Smith JC, Finn MC. The possible role of mast cells (allergy) in the production of keloid and hypertrophic scarring. I Burn Care Rehabil 1987;8:126-31.

21 Leiferman KM, Ackerman SJ, Sampson HA, et al. Dermal deposition of eosinophil granule major basic protein in atopic dermatitis. N Engl f Med 1985;313:282-5.

22 Armbrust T, Batusic D, Ringe B, et al. Mast cell distribution in human liver disease and experimental rat liver fibrosis. Indications for mast cell participation in development of liver fibrosis. F Hepatol 1991;26:1042-54

23 Chanez P, Lacoste JY, Guillot B, et al. Mast cells' contribution to the fibrosing alveolitis of the scleroderma lung. $A m$ Rev Respir Dis 1993;147:1497-502.

24 Hunt LW, Colby TV, Weiler DA, et al. Immunofluorescent staining for mast cells in idiopathic pulmonary fibrosis: staining for mast cells in idiopathic pulmonary fibrosis: cell tryptase. Mayo Clin Proc 1992;67:941-8.

25 Turlington BS, Edwards WD. Quantitation of mast cells in 100 normal and 92 diseased human hearts. Implications for interpretation of endomyocardial biopsy specimens. $A m$ f Cardiovasc Pathol 1988;2:151-7.

26 Yousem SA. The potential role of mast cells in lung allograft rejection. Hum Pathol 1997;28:179-82.

$27 \mathrm{Qu} \mathrm{Z}$, Liebler JM, Powers MR, et al. Mast cells are a major source of basic fibroblast growth factor in chronic inflammation and cutaneous haemangioma. Am 7 Pathol 1995;147:564-73.

$28 \mathrm{Hu}$ ZQ, Yamazaki T, Cai Z, et al. Mast cells display natural suppressor activity partially by releasing transforming growth factor-beta. Immunology 1994;82:482-6.

29 Johnson JL, Jackson CL, Angelini GD, et al. Activation of matrix-degrading metalloproteinases by mast cell proteases in atherosclerotic plaques. Arterioscler Thromb Vasc Biol 1998;18:1707-15.

30 Cairns JA, Walls AF. Mast cell tryptase stimulates the synthesis of type I collagen in human lung fibroblasts. $\mathcal{F}$ synthesis of type I collagen
Clin Invest 1997;99:1313-21.

31 Gruber BL, Kew RR, Jelaska A, et al. Human mast cells activate fibroblasts: tryptase is a fibrogenic factor stimulating collagen messenger ribonucleic acid synthesis and fibroblast chemotaxis. F Immunol 1997;158:2310-17.

32 Taipale J, Lohi J, Saarinen J, et al. Human mast cell chymase and leukocyte elastase release latent transforming growth factor- $\beta 1$ from the extracellular matrix of cultured human epithelial and endothelial cells. F Biol Chem 1995;270: 4689-96.

33 Ferrao AV, Mason RM. The effect of heparin on cell proliferation and type-I collagen synthesis by adult human dermal fibroblasts. Biochim Biophys Acta 1993;1180:22530.

34 Norrby D. Effect of heparin, histamine and serotonin on the density-dependent inhibition of replication in two fibroblastic cell lines. Virchows Arch B Cell Pathol 1973;15: $75-93$.
35 Trautmann A, Krohne G, Brocker EB, et al. Human mast cells augment fibroblast proliferation by heterotypic 5053-7.

36 Greenberg G, Burnstock G. A novel cell-to-cell interaction between mast cells and other cell types. Exp Cell Res 1983; 147:1-13

37 Dethlefson SM, Mulliken JB, Glowacki J. An ultrastructural study of mast cell interactions in haemangiomas. Ultrastruct Pathol 1986;10:175-83.

38 Pitt MA, Roberts ISD, Curry A. Spindle cell and pleomorphic lipoma: an ultrastructural study. Ultrastruct Pathol 1995;19:475-80.

39 Kirkpatrick CJ, Curry A. Interaction between mast cells and perineural fibroblasts in neurofibroma: new insights in to mast cell function. Pathol Res Pract 1988;183:453-8.

40 Agodoa LY, Eggers PW. Renal replacement therapy in the United States: data from the United States renal data system. Am ₹ Kidney Dis 1995;25:119-33.

41 Mallick NP, Jones E, Selwood N. The European (European Dialysis and Transplantation Association-European Renal Dialysis and Transplantation Association-European Renal
Association) registry. Am $\mathcal{F}$ Kidney Dis 1995;25:176-87.

42 Wehrmann M, Bohle A, Bogenschutz O, et al. Long term prognosis of chronic idiopathic membranous glomerulonephritis. Clin Nephrol 1989;31:67-76.

43 Bohle A, Mackensen-Haen S, Gise H. Significance of tubuointerstitial changes in the renal cortex for the excretory function and concentration ability of the kidney: a
morphometric contribution. Am $₹$ Nephrol 1987;7:421-33.

44 Austin HA, Boumpas DT, Vaughan EM, et al. Predicting renal outcomes in severe lupus nephritis: contributions of clinical and histological data. Kidney Int 1994;45:544-50.

45 Roberts ISD, Burrows C, Shanks JH, et al. Interstitial myofibroblasts: predictors of progression in membranous nephropathy. F Clin Pathol 1997;50:123-7.

46 Alexopoulos E, Seron D, Hartley RB, et al. Immune mechanisms in idiopathic membranous nephropathy: the role of interstitial infiltrates. Am f Kidney Dis 1989;13:404-12.

47 Bohle A, Muller GA, Wehrmann M, et al. Pathogenesis of chronic renal failure in the primary glomerulopathies, renal vasculopathies and chronic interstitial nephritides. Kidney Int 1996:49:S2-9.

48 Alpers CE, Hudkins KL, Floege J, et al. Human renal cortical interstitial cells with some features of smooth muscle cells participate in tubulointerstitial and crescentic injury. $\mathcal{F}$ Am Soc Nephrol 1994;5:201-10.

49 Floege J, Grone HJ. Progression of renal failure: what is the role of cytokines? Nephrol Dial Transplant 1995;10:1575-86.

50 Johnson DW, Saunders HJ, Baxter RC, et al. Paracrine stimulation of human renal fibroblasts by proximal tubule cells. Kidney Int 1998;54:747-57.

51 Ong ACM, Fine LG. Tubular derived growth factors and cytokines in the pathogenesis of tubulointersitial fibrosis: implications for human disease progression. Am f Kidney Dis 1994;23:205-9.

52 Strutz F, Neilson EG. The role of lymphocytes in the progression of interstitial disease. Kidney Int 1994;45: S106-10.

53 Ng Y-Y, Huang T-P, Yang W-C, et al. Tubular epithelialmyofibroblast transdifferentiation in progressive tubulointerstitial fibrosis in $5 / 6$ nephrectomised rats. Kidney Int 1998;54:864-76.

54 Tang WW, Van GY, Qi M. Myofibroblast and alpha $a_{1}$ (III)collagen expression in experimental tubulointerstitial nephritis. Kidney Int 1997;51:926-31.

55 Schena FP, Gesualdo L, Grandaliano G, et al. Progression of renal damage in human glomerulonephritides: is there sleight of hand in winning the game? Kidney Int 1997; 52:1439-57.

56 Brenchley PEC, Short CD, Roberts ISD. Is persistent TGF $\beta-1$ expression the mechanism responsible for chronic renal allograft loss? Nephrol Dial Transplant 1998;13:548-51.

57 Ruger BM, Hasan Q, Greenhill NS, et al. Mast cells and type VIII collagen in human diabetic nephropathy. Diabetologia 1996;39:1215-22.

58 Ehara T, Shigematsu H. Contribution of mast cells to the tubulointerstitial lesions in IgA nephritis. Kidney Int 1998; 54:1675-83.

59 Wingren U, Enerback L. Mucosal mast cell of the rat intestine: a re-evaluation of fixation and staining properties, with special reference to protein blocking and solubility of the granular glycosaminoglycan. Histochem $\mathcal{F}$ 1983;15:57182 .

60 Okazaki T, Hirota S, Xu ZD, et al. Increase of mast cells in the liver and lung may be associated with but not a cause of fibrosis: demonstration using mast cell deficient Ws/Ws rats. Lab Invest 1998;78:1431-8.

61 Lyon M, Rushton G, Gallagher JT. The interaction of the transforming growth factor-betas with heparin/heparan sulfate is isoform-specific. F Biol Chem 1997;272:18000-6.

62 Kitamura Y, Go S, Hatanaka S. Decrease of mast cells in $\mathrm{W} / \mathrm{W}^{\mathrm{v}}$ mice and their increase by bone marrow transplantation. Blood 1978;52:447-52.

63 Walker MA, Harley RA, Leroy EC. Inhibition of fibrosis in TSK mice by blocking mast cell degranulation. F Rheumatol 1987;14:299-301. 